\title{
Fabrication of Superhydrophobic AA5052 Aluminum Alloy Surface with Improved Corrosion Resistance and Self Cleaning Property
}

\author{
Qian Zhao ${ }^{1}$, Tiantian Tang ${ }^{2}$ and Fang Wang ${ }^{2, *}$ \\ 1 Shaanxi Key Laboratory of Disaster Monitoring and Mechanism Simulation, Baoji University of Arts and \\ Sciences, Baoji 721013, China; qianzhao@bjwlxy.cn \\ 2 College of Chemistry \& Pharmacy, Northwest A\&F University, Yangling 712100, China; \\ tangtiantian1020@foxmail.com \\ * Correspondence: wangfang4070@nwsuaf.edu.cn; Tel.: +86-29-8709-2226; Fax: +86-29-8709-2082
}

Received: 10 September 2018; Accepted: 26 October 2018; Published: 31 October 2018

\begin{abstract}
The development of a self-cleaning and corrosion resistant superhydrophobic coating for aluminum alloy surfaces that is durable in aggressive conditions has attracted great interest in materials science. In the present study, a superphydrophobic film was fabricated on an AA5052 aluminum alloy surface by the electrodeposition of Ni-Co alloy coating, followed by modification with 6-(N-allyl-1,1,2,2-tetrahydro-perfluorodecyl) amino-1,3,5-triazine-2,4-dithiol monosodium (AF17N). The surface morphology and characteristics of the composite coatings were investigated by means of scanning electron microscopy (SEM), energy dispersive X-ray spectrum (EDS), atomic force microscope (AFM) and contact angle (CA). The corrosion resistance of the coatings was assessed by electrochemical tests. The results showed that the surface exhibited excellent superhydrophobicity and self-cleaning performance with a contact angle maintained at $160^{\circ}$ after exposed to the atmosphere for 240 days. Moreover, the superhydrophobic coatings significantly improved the corrosion resistant performance of AA5052 aluminum alloy substrate in $3.5 \mathrm{wt} . \%$ $\mathrm{NaCl}$ solution.
\end{abstract}

Keywords: superhydrophobic surface; aluminum alloy; corrosion resistance; self-cleaning

\section{Introduction}

Aluminum and its alloys have widespread engineering applications owing to their high strength-to-density ratio, ductility, low weight and formability $[1,2]$. The wrought aluminum-zinc-magnesium-copper series alloys have been largely employed for production of the AA5052 chemical equipment, pressure vessels, food packaging, fan blades, coding utilities, automotive parts, etc. [3,4]. However, because the potential of aluminum alloys are more negative compared to other conventional metals, they are highly susceptible to corrosion, especially in moist environments, and undergo more rapid deterioration due to localized corrosion than their homogeneous counterparts. This has seriously limited their widespread applications [5]. Increasing the hydrophobicity of metal surfaces can reduce their interactions with corrosive media such as water, thereby enhancing their corrosion resistance [6]. Therefore, a self-cleaning superhydrophobic surface could be a potential solution to solve the functionality and aesthetic appearance problems caused by corrosion and contamination.

In recent years, superhydrophobic surfaces, which exhibit a water contact angle (CA) above $150^{\circ}$ and a sliding angle (SA) below $10^{\circ}$, have aroused an enormous amount of interest in both fundamental research and potential applications because of their unique characteristics, such as self-cleaning [7], anti-icing [8,9], oil-water separation [10,11], antifouling property [12] and anticorrosion [13]. Inspired 
by biological materials in nature, such as lotus leaves [14], a variety of metallic surfaces with super-hydrophobic property have been fabricated through the combination of surface micro/nano structures and low surface energy materials $[15,16]$.

Wettability on the surface of the material mainly depends on the surface chemical properties and surface microstructure [17]; thus, the improvement of the hydrophobicity of material surface is often achieved by changing the surface microscopic structure and lowering the surface energy $[18,19]$. Up to now, artificial super hydrophobic surfaces on aluminum and its alloy substrates have been created by various methods [20-22]. However, practical use is often interrupted by time-consuming processes, low mechanical strength or expensive cost. Additionally, most approaches involve the use of fluorinated compounds, which are costly and environmentally undesirable. Herein, a simple, environmental-friendly and cost-effective approach is still a much-needed study.

Triazinedithiol compounds, as a kind of environmentally friendly compounds, have attracted many researchers' attention during the past decade for their good properties such as high reactive, low cost, good adhesion and dielectric property on a variety of metal category [23-25]. Specifically, the triazinedithiol polymeric nanofilm exhibits excellent hydrophobicity and corrosion resistance in previous studies [26].

In the present paper, we reported a simple and efficient process for the construction of a superhydrophobic surface on an AA5052 aluminum alloy, wherein Ni-Co platings were electrodeposited on the pretreated AA5052 substrate surface to first form hierarchical micro/nano structures, which was then modified using an environmentally-friendly long-chain triazinedithiol compound (AF17N) with a low surface energy. Additionally, the surface morphology, self-cleaning characteristics and anticorrosion behavior of the obtained surface was investigated.

\section{Materials and Methods}

\subsection{Materials}

Aluminum alloys (AA5052, size $50 \times 20 \times 0.3 \mathrm{~mm}^{3}$, chemical composition: Cu: 0.1 wt. $\%$, Si: 0.2 wt. $\%$, Fe: 0.4 wt.\%, Mn: 0.1 wt.\%, Mg: 2.8 wt. $\%$, Zn: 0.1 wt.\%, Cr: 0.3 wt.\%, other impurities 0.15 wt.\%, and the remaining element $\mathrm{Al}$ ) were used as substrates. 6-(N-allyl-1,1,2,2-tetrahydroperfluorodecyl) amino-1,3,5-triazine-2,4-dithiol monosodium (AF17N) was prepared by the reaction between 6-(N-allyl-1,1,2,2-tetrahydroperfluorodecyl)-amine-1,3,5-triazine-2,4-dichloride and $\mathrm{NaSH}$, according to the method described previously in [27]. The structure of AF17N is shown in Figure 1. The nickel plate with a purity of $99.99 \mathrm{wt} . \%$ was used as the anode in the electrodeposition process. The other chemical reagents were obtained from Aladdin Reagent Database Inc., Shanghai, China. All regents were of analytical grade and deionized water was used for all of the experiments.

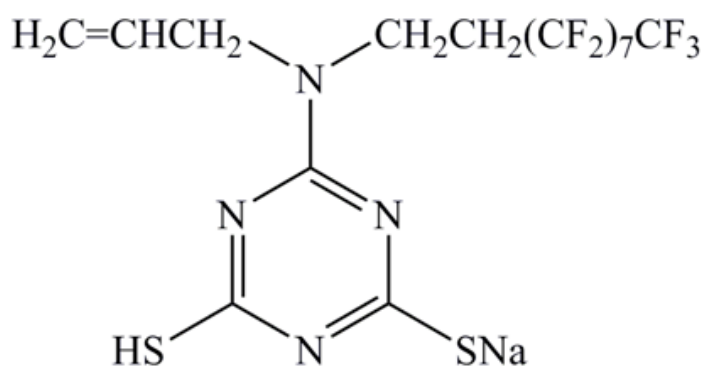

Figure 1. Structure of amino-1,3,5-triazine-2,4-dithiol monosodium (AF17N).

\subsection{Preparation of the Superhydrophobic Coatings on AA5052 Surface}

Synthesis of the superhydrophobic coatings on the AA5052 surface includes two steps: first, creation of a rough AA5052 surface by electrodepositing a Ni-Co plating; second, lowering the surface energy with AF17N. 
The AA5052 substrate was initially degreased in an alkaline solution containing $10 \mathrm{~g} \mathrm{~L}^{-1}$ $\mathrm{Na}_{3} \mathrm{PO}_{4}, 10 \mathrm{~g} \mathrm{~L}^{-1} \mathrm{Na}_{2} \mathrm{CO}_{3}$ at $70{ }^{\circ} \mathrm{C}$ for $1.5 \mathrm{~min}$, and then rinsed with deionized water. Subsequently, the AA5052 substrate was immersed in a solution (which contained $10 \mathrm{~g} \mathrm{~L}^{-1} \mathrm{NiCO}_{3} \cdot 2 \mathrm{NiO}_{2} \mathrm{H}_{2} \cdot 4 \mathrm{H}_{2} \mathrm{O}$, $5 \mathrm{~g} \mathrm{~L}^{-1} \mathrm{C}_{6} \mathrm{H}_{8} \mathrm{O}_{7} \cdot \mathrm{H}_{2} \mathrm{O}, 0.001 \mathrm{~g} \mathrm{~L}^{-1}\left(\mathrm{H}_{4} \mathrm{~N}\right)_{2} \mathrm{~S}, 20 \mathrm{~g} \mathrm{~L}^{-1} \mathrm{NaH}_{2} \mathrm{PO}_{2} \cdot \mathrm{H}_{2} \mathrm{O}$ and $\left.30 \mathrm{~mL} \mathrm{~L}^{-1} \mathrm{NH}_{3} \cdot \mathrm{H}_{2} \mathrm{O}\right)$ for $40 \mathrm{~min}$ at $75{ }^{\circ} \mathrm{C}$ to form a electroless nickel coating [28]. Then, the samples were washed with deionized water, and last, dried in open air. The Ni-Co plating was electrodeposited using an electrochemical workstation (CHI 660C, CH Instrument, Shanghai, China) under direct current conditions. The electrodeposition was performed by a three-electrode cell, with the as-prepared samples with electroless nickel coating as a cathode, the saturated calomel electrode (SCE) as a reference electrode and the nickel plate was used as anode. The optimized bath composition and other parameters of electrodeposition Ni-Co alloy plating are given in Table 1.

Table 1. Bath compositions and operating conditions for electrodeposition of Ni-Co.

\begin{tabular}{ccc}
\hline Compositions & Concentration $\left(\mathbf{g ~ L}^{-\mathbf{1}}\right)$ & Conditions \\
\hline $\mathrm{NiCl}_{2} \cdot 6 \mathrm{H}_{2} \mathrm{O}$ & 113 & Current densities: $3 \mathrm{~mA} \mathrm{~cm}^{-2}$ \\
$\mathrm{CoCl}_{2} \cdot 6 \mathrm{H}_{2} \mathrm{O}$ & 8 & pH: 3.6 \\
$\mathrm{C}_{2} \mathrm{H}_{8} \mathrm{~N}_{2} \cdot 2 \mathrm{HCl}$ & 100 & Temperature: $50{ }^{\circ} \mathrm{C}$ \\
$\mathrm{H}_{3} \mathrm{BO}_{3}$ & 15 & Time: $360 \mathrm{~s}$ \\
\hline
\end{tabular}

Subsequently, the as-prepared AA5052 samples with Ni-Co alloy coatings were modified with $1 \mathrm{mM}$ AF17N solution for $2 \mathrm{~h}$ at room temperature $\left(25^{\circ} \mathrm{C} \pm 1{ }^{\circ} \mathrm{C}\right)$. Finally, the samples were rinsed with deionized water and dried in an oven $\left(150^{\circ} \mathrm{C}, 15 \mathrm{~min}\right)$ for further characterization.

\subsection{Characterization}

The water contact angles (CAs) and sliding angles (SAs) were measured with a telescopic goniometer (HARKE-SPCAX1). The volume of water drops was $3 \mu \mathrm{L}$. The values reported were the average values by measuring five different positions on each sample. A field emission scanning electron microscope (FESEM; HITACHI S-4800, Tokyo, Japan) and atomic force microscope (AFM; JSM-6360LV; JEOL, Tokyo, Japan) were used to characterize the surface morphologies. Scanning electron microscopy (SEM) with an energy dispersive X-ray spectrum (EDS) was used to characterize the surface chemical composition. The potentiodynamic polarization curves and electrochemical impedance spectroscopic (EIS) were performed on an electrochemical workstation (CHI 660C, $\mathrm{CH}$ Instrument, Shanghai, China) in a cell with $3.5 \mathrm{wt} . \% \mathrm{NaCl}$ solution at room temperature $\left(25^{\circ} \mathrm{C} \pm 1{ }^{\circ} \mathrm{C}\right)$. A three-electrode configuration was employed in all of the electrochemical tests, which consisted of the sample as the working electrode $\left(1 \mathrm{~cm}^{2}\right)$, a graphite plate as the counter electrode and a saturated calomel electrode (SCE) as the reference electrode. The polarization curves were recorded with a sweep rate of $1 \mathrm{mV} \mathrm{s}^{-1}$. EIS plots were performed in the frequency range between $100 \mathrm{kHz}$ (high frequency area) and $10 \mathrm{mHz}$ (low frequency area) with a sine-wave amplitude of $5 \mathrm{mV}$. The polarization curves and EIS spectra were fitted by using the CorrTest software. Cyclic voltammetry (CV) was conducted between the potential region from $-0.7 \mathrm{~V}$ to $0.7 \mathrm{~V}$ at $20 \mathrm{mV} \mathrm{s}^{-1}$ in $0.1 \mathrm{M} \mathrm{NaOH}$ aqueous solution for three circles. All the electrochemical tests were normally repeated at least three times under the same conditions, indicating that they presented reasonable reproducibility.

\section{Results}

\subsection{Surface Morphology and Chemical Compositions}

The surface wettability of the as-obtained superhydrophobic surface was studied by CA and SA measurements. The images of the water droplets on various surfaces were shown in Figure 2. The bare aluminum surface exhibited a CA of $33.5^{\circ} \pm 1.6^{\circ}$ (Figure 2a). After electrodeposition of $\mathrm{Ni}-\mathrm{Co}$, the sample surface exhibited superhydrophilicity with a CA of approximately $5^{\circ}$ (Figure $2 \mathrm{~b}$ ). 
Figure $2 \mathrm{c}$ shows that the static water droplet is in an approximately spherical shape on the level as-prepared surface and the water contact angle is as high as $160^{\circ}$, which is much higher than the bare aluminum alloy surface. Additionally, the advancing angle is about $161.3^{\circ}$ and the receding angle is $158.7^{\circ}$. After modification with AF17N, the wettability changes from superhydrophilicity to superhydrophobicity. From Figure $2 \mathrm{~d}$, it can be observed that a $3 \mu \mathrm{L}$ water droplet was bouncing on the surface and finally rolled off the nearly horizontal surface immediately without any adhesion, indicating that the superhydrophobic surface has an ultra-low sliding angle of about $1.0^{\circ}$. This means that the as-prepared superhydrophobic surface possesses excellent water-repellent property.

a

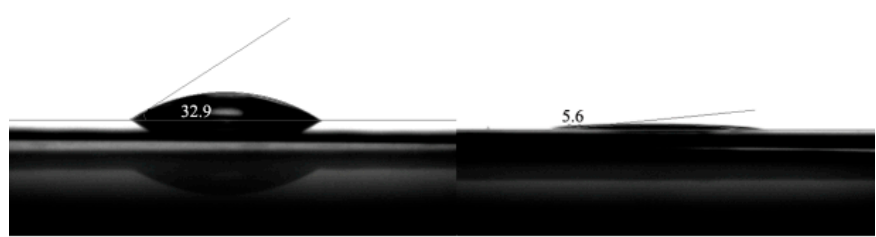

c

$\mathrm{b}$

d
$\mathrm{CA} \approx 160^{\circ} \quad \mathrm{SA} \approx 1^{\circ}$

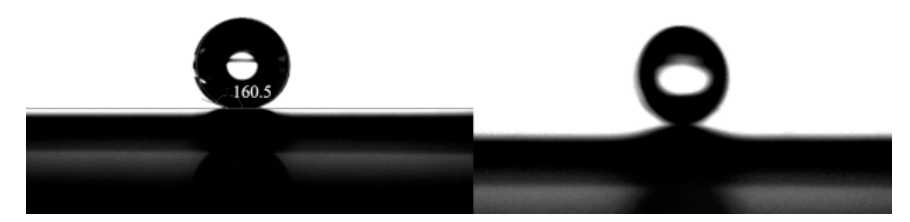

Figure 2. The contact angle (CA) images of (a) bare aluminum alloy; (b) electrodeposited Ni-Co plating; (c) superhydrophobic surface; (d) snapshot photograph of a water droplet rolling off on the tilted superhydrophobic surface.

This phenomenon could be explained by the Cassie-Baxter equation [29]:

$$
\cos \theta_{r}=f_{1} \cos \theta-f_{2}
$$

where $f_{1}$ and $f_{2}$ are fractional areas of the solid and air on the surface, respectively (i.e., $f_{1}+f_{2}$ $=1) ; \theta_{\mathrm{r}}$ and $\theta$ are the water contact angles of the rough heterogeneous surfaces and smooth solid surfaces. According to Equation (1), with increasing the air surface fraction $f_{2}$, the solid surface fraction $f_{1}$ decreases, however, the contact angle of the rough surface increases. The air trapped in the grooves could reduce the contact area $\left(f_{1}\right)$ between a water droplet and solid surface. Consequently, the hydrophobicity of the surface is enormously enhanced, and a high contact angle and low sliding angle would be obtained.

The SEM images of morphologies with different magnifications of the as-prepared superhydrophobic surface are given in Figure 3. It can be seen that the surface consists of two different microstructures. There are large amounts of small microparticles located on the electroless nickel coating (Figure 3a). Careful inspection of the surface reveals that the microparticles were cluster-like microclusters (Figure $3 b$ ) and the surface was completely and compactly covered with these cluster-like microclusters. From observing Figure 3c,d, it can be easily found that the cluster structures were composed of numerous irregular conelike structures with a width average length of 100-200 nm, indicating that the cluster-like structures have hierarchical micro/nano structures. More importantly, these hierarchical micro/nano structures can generate numerous grooves in which the air can be trapped easily, which can lead to the larger CA and smaller SA. 


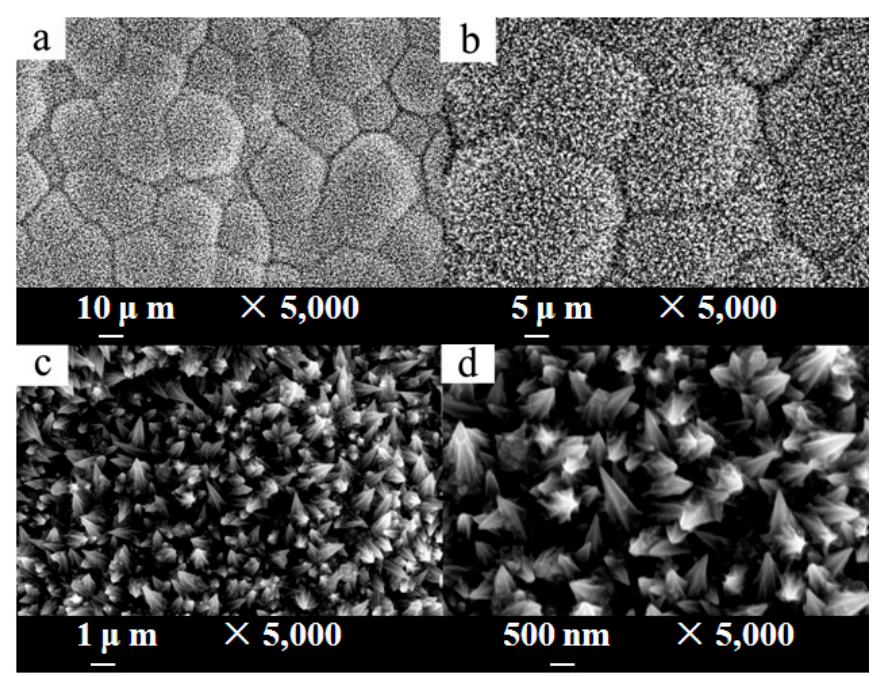

Figure 3. Scanning electron microscopy (SEM) images of the as-prepared superhydrophobic surface with different magnifications. (a) 5,000 times; (b) 10,000 times; (c) 50,000 times; (d) 100,000 times.

Chemical compositions of the surfaces were analyzed by using EDS (Figure 4). Figure 4a shows the EDS image of bare aluminum alloy. The EDS spectrum shows that no other evident peaks apart from that of $\mathrm{Al}$, which indicates the surface is mainly composed of $\mathrm{Al}$ element. The EDS spectrum in Figure $4 \mathrm{~b}$ reveals the additional presence of $\mathrm{P}$ and $\mathrm{Ni}$ elements, suggesting considerable changes in the composition of the aluminum alloy surface after the electroless nickel. In order to testify the AF17N, Figure 4c,d shows the EDS spectrum of the surface unmodified and modified by AF17N monomers after electrodeposition Ni-Co alloy plating. The EDS spectrum of as-perpared superhydrophobic aluminum surface in Figure 4d reveals the appearance of C, N, O, F, Al, P, Co and Ni elements. The presence of $\mathrm{N}$ and $\mathrm{F}$ elements are attributed to the $\mathrm{AF} 17 \mathrm{~N}$, indicates that the surface has been covered with AF17N polymeric nanofilm after chemical modification, showing that the AF17N has been successfully adsorbed onto the surface (Figure 4d).
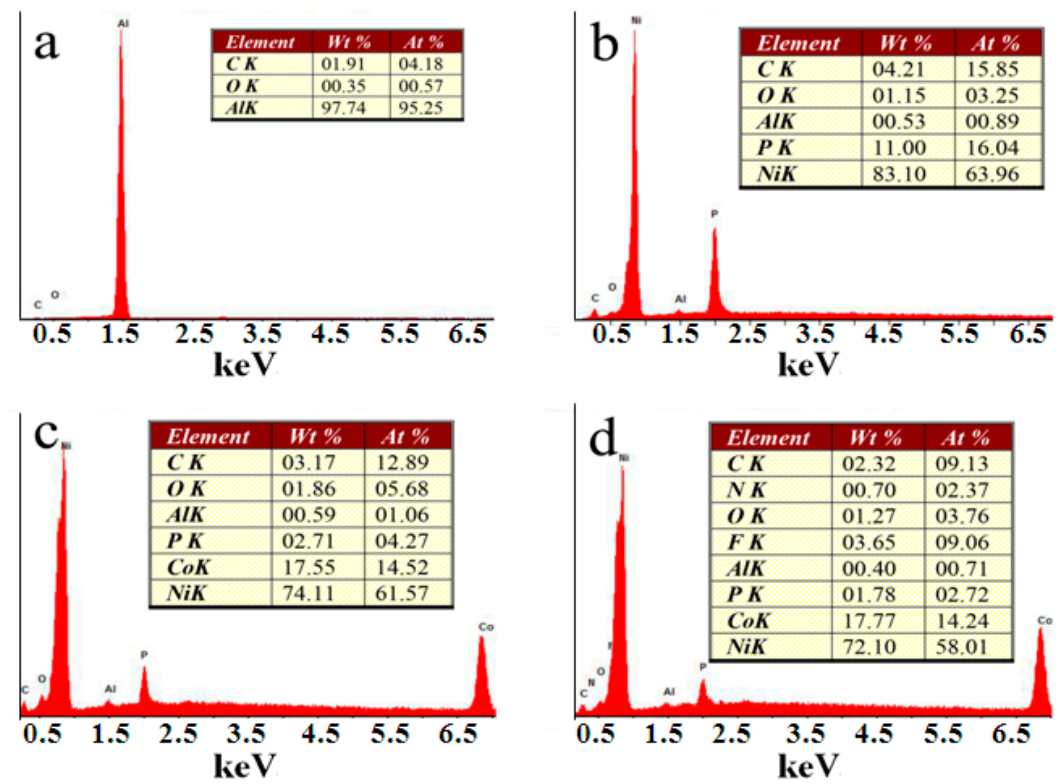

Figure 4. Energy dispersive X-ray spectrum (EDS) spectra and its corresponding element content. (a) bare aluminum alloy; (b) electroless Ni coating;(c) electrodeposited Ni-Co plating; (d) superhydrophobic surface after modified AF17N. 
In order to find out the reason for the change of the wettability, SEM and AFM were applied. Figure 5 shows the SEM and AFM images of the aluminum alloy surface under different treatment conditions. Figure 5 a,e demonstrate the micrographs of the bare aluminum alloy after pretreament. It is clear that the bare aluminum alloy surface is relatively flat without protuberance (surface roughness $R_{\mathrm{a}}$ is about $25.7 \mathrm{~nm}$ ). According to Figure $5 \mathrm{~b}, \mathrm{f}$, after electroless nickel coating, the aluminum alloy is covered with micro-sphere array structures, which have an average size of $500 \mathrm{~nm}$ in height and $2 \mu \mathrm{m}$ in diameter. Simultaneously, the surface roughness distinctly increased (surface roughness $R_{\mathrm{a}}$ is about $76.7 \mathrm{~nm}$ ). After electrodeposition of Ni-Co alloy plating, it is obvious that the nickel coating surface was completely and densely covered with enormous small particles. Moreover, the Ni-Co alloy plating has a frosting surface morphology compared with the nickel coating, which may be attributed to the smaller average size for the $\mathrm{Ni}-\mathrm{Co}$ particles. It can be seen that the surface becomes quite rough (surface roughness $R_{\mathrm{a}}$ is about $92.5 \mathrm{~nm}$ ) and develops mountain-like structure with the size of $864 \mathrm{~nm}$ in height (Figure 5g). The rough surface could then be changed from superhydrophilicity to superhydrophobic after modification by AF17N. It can be easily seen that the surface morphologies of the resulting superhydrophobic surface shown in Figure 5d,h are nearly the same as that of the Ni-Co alloy plating. This means that the surface morphologies of the Ni-Co alloy plating before and after modification with AF17N show hardly any change. This is because only a small amount of AF17N was absorbed onto the Ni-Co alloy plating. However, the surface roughness slightly decreased (surface roughness $R_{\mathrm{a}}$ is about $84.3 \mathrm{~nm}$ ), owing to the AF17N might fill in some nano-scale pores of the rough surface (Figure $5 \mathrm{~h}$ ).

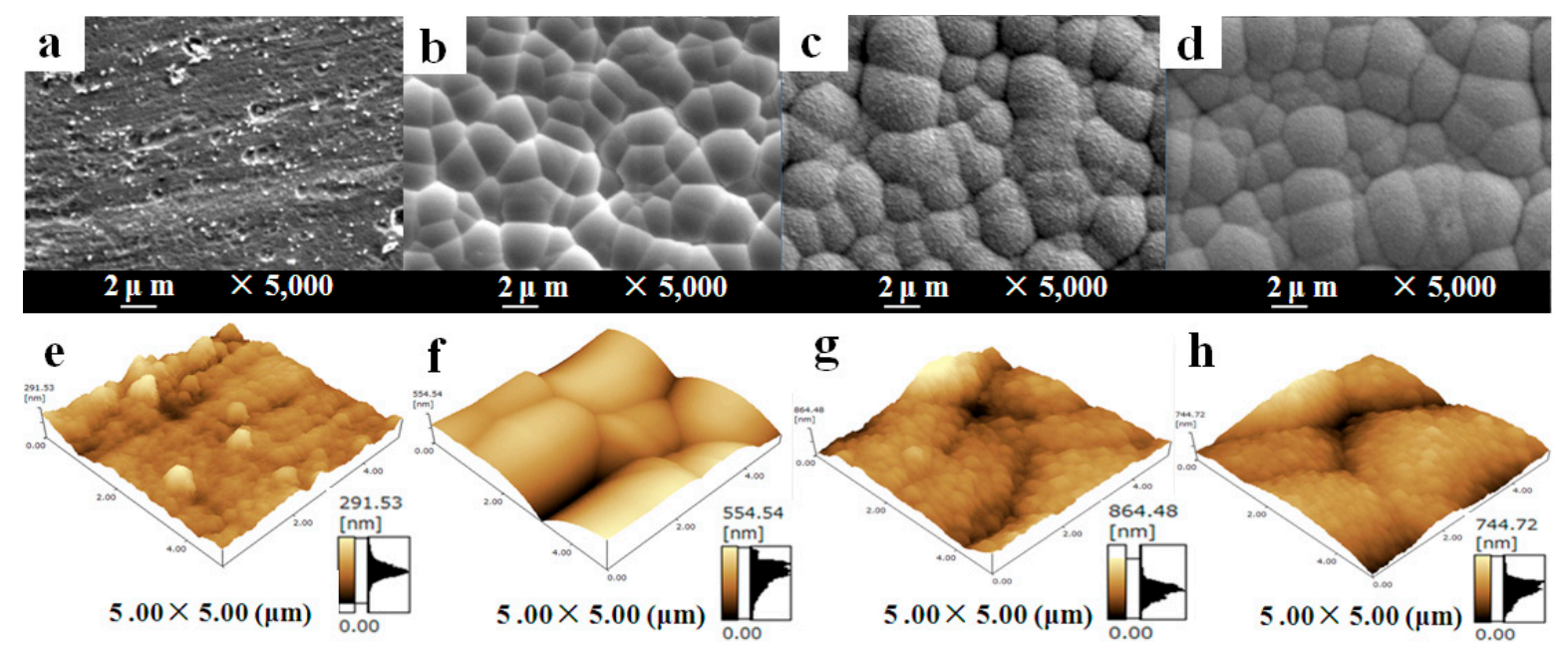

Figure 5. The SEM (a-d) and its corresponding atomic force microscope (AFM) (e-h) images. (a-e) bare aluminum alloy; (b-f) electroless Ni coating; (c-f) electrodeposited Ni-Co plating; (d-h) superhydrophobic surface.

\subsection{Chemical Stability and Corrosion Resistance}

To elucidate the stability of sample surfaces, the superhydrophobicity of the obtained surfaces were exposed to open air (room temperature of $24-26^{\circ} \mathrm{C}$ and relative humidity of $40 \%-50 \%$ ) and the contact angles were measured. Figure 6 shows the variation in the water contact angles of the as-prepared superhydrophobic surface with different exposure times. The water contact angles change from $151.3^{\circ} \pm 2.5^{\circ}$ to $155.6^{\circ} \pm 2.1^{\circ}$ after 4 weeks. When exposure was more than 16 weeks, the water contact angles increased, rather than decreased, from $155.6^{\circ}$ to $160.0^{\circ}$. The results indicate that the as-obtained surface exhibit long-term stability; this is of great importance to the practical application of superhydrophobic surface.

Corrosion resistance ability was performed on the superhydrophobic AA5052 surface using the potentiodynamic polarization and electrochemical impedance spectroscopy (EIS) method. Figure 7 depicts the potentiodynamic polarization curves for the bare aluminum alloy substrate and the 
as-prepared superhydrophobic surface in neutral $3.5 \mathrm{wt} . \% \mathrm{NaCl}$ solution. The relevant electrochemical parameters including corrosion potential and corrosion current density derived from polarization curves using the Tafel extrapolation method are listed in Table 2. Corrosion potential ( $\left.E_{\text {corr }}\right)$, corrosion current density $\left(I_{\text {corr }}\right)$, corrosion rate and protection efficiency $(\mathrm{PE})$ are often applied to evaluate the corrosion protective property of the coatings. According to Table 2, the result clearly shows that the corrosion potential $\left(E_{\text {corr }}\right)$ increase in positive direction from $-0.69 \mathrm{~V}$ of the bare aluminum alloy to $-0.28 \mathrm{~V}$ of the as-prepared superhydrophobic surface. Additionally, the corrosion current density $\left(I_{\text {corr }}\right)$ decreased from $1.03 \times 10^{-2} \mathrm{~A} \mathrm{~cm}^{-2}$ of bare aluminum alloy to $6.76 \times 10^{-5} \mathrm{~A} \mathrm{~cm}^{-2}$ of as-prepared superhydrophobic surface. Moreover, its corrosion rate is merely $0.6 \%$ of the bare aluminum alloy.

The protection efficiency $(\mathrm{PE})$ was calculated by using the expression:

$$
P E(\%)=100 \times\left[1-\left(i / i_{0}\right)\right]
$$

where $i$ and $i_{0}$ are the corrosion current density of aluminum alloy with as-prepared super-hydrophobic surface and bare aluminum alloy, respectively. The protection efficiency calculated from potentiodynamic polarization data is found to be as high as $99.34 \%$, demonstrating that the superhydrophobic surface significantly improves the corrosion resistance of aluminum alloys.

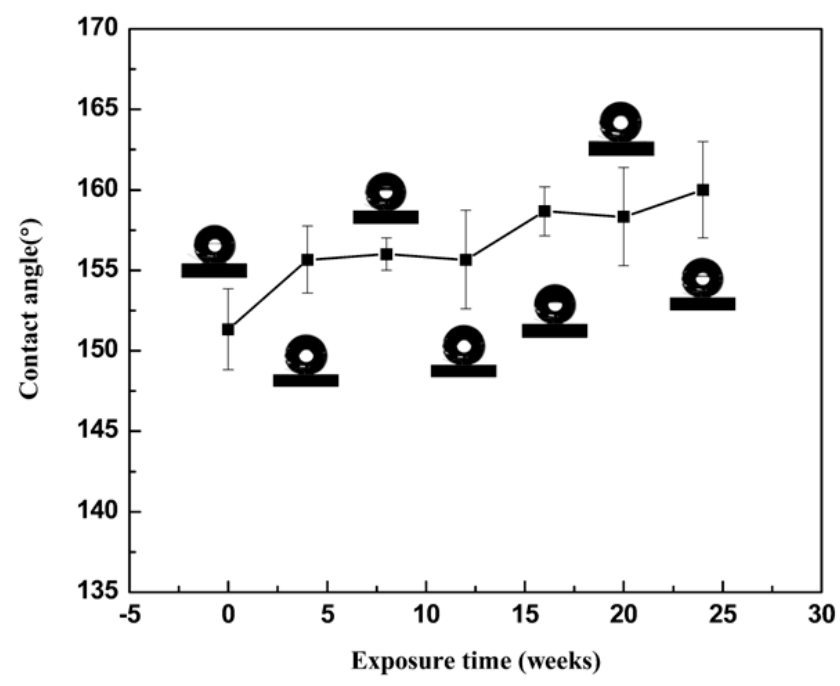

Figure 6. Variation in the water contact angles of samples surfaces with the exposure time.

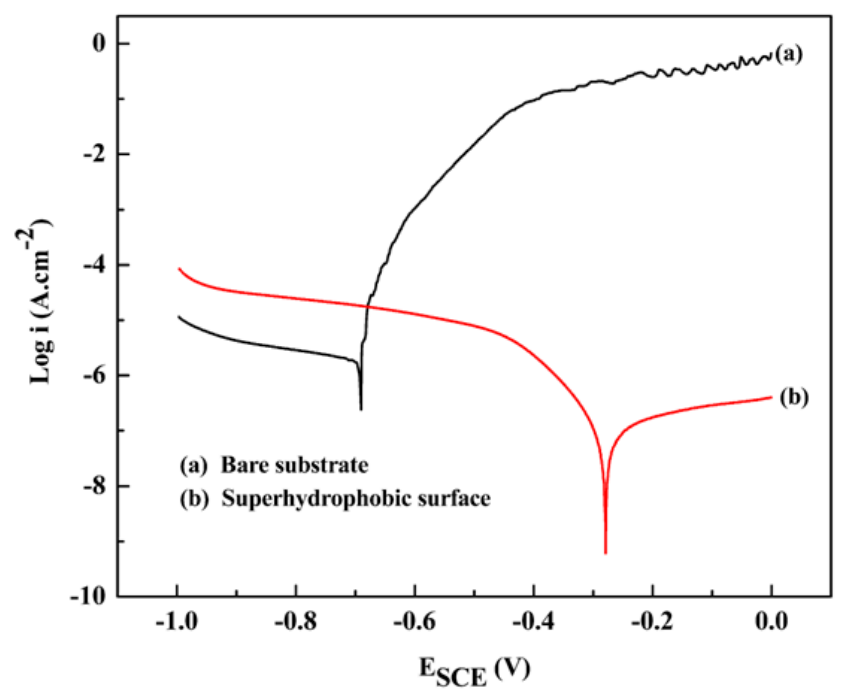

Figure 7. Potentiodynamic polarization curves of bare AA5052 aluminum alloy and superhydrophobic surface in 3.5 wt. $\% \mathrm{NaCl}$ solution. 
Table 2. Electrochemical parameters of potentiodynamic polarization curves.

\begin{tabular}{|c|c|c|c|c|}
\hline Sample & $E_{\text {corr }}(\mathrm{V})$ & $I_{\text {corr }}\left(\mathrm{A} \mathrm{cm}^{-2}\right)$ & Corrision Rate $\left(\mathrm{mm} \mathrm{a}^{-1}\right)$ & PE (\%) \\
\hline Bare aluminum alloy & -0.69 & $1.03 \times 10^{-2}$ & $1.12 \times 10^{-1}$ & - \\
\hline Superhydrophobic & -0.28 & $6.76 \times 10^{-5}$ & $7.39 \times 10^{-4}$ & 99.34 \\
\hline
\end{tabular}

Figure 8 shows the Nyquist plots and Bode plots of the bare aluminum alloy and the as-prepared superhydrophobic surface. The results show quite different capacitive loops in the Nyquist plots. It is well known that the diameter of the capacitive loop represents the polarization resistance of the work electrode. As shown in Figure 8, the diameter of the as-prepared surface is obviously bigger than that of the bare substrate, which is attributed to a protective surface film of Ni-Co plating and AF17N polymeric nanofilms. Furthermore, we used the Bode plots to continue the investigation. From Figure 8, it can be observed that the impedance modulus $|Z|$ of the as-prepared superhydrophobic surface is more than one order of magnitude higher than bare substrate, indicating that the superhydrophobic coating retards the formation of the corrosion products. Simultaneously, this result is consistent with that derived from the potentiodynamic polarization curves, showing that superhydrophobic surface can supply excellent corrosion protection for bare aluminum alloy in $3.5 \mathrm{wt} . \% \mathrm{NaCl}$ solution.
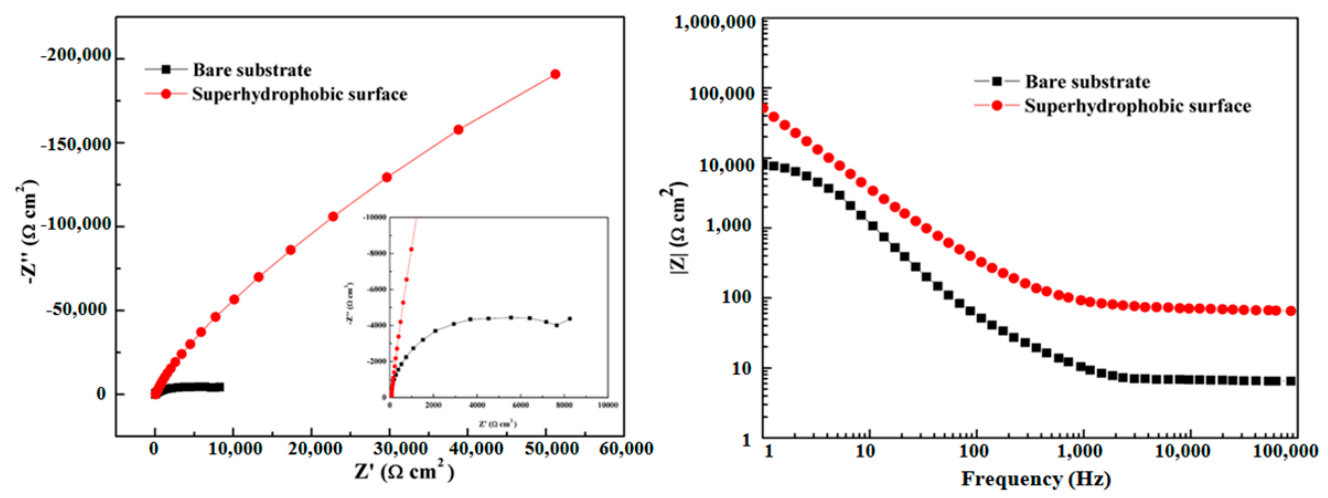

Figure 8. Nyquist plots and Bode plots of bare AA5052 aluminum alloy and superhydrophobic surface in 3.5 wt. $\% \mathrm{NaCl}$ solution.

For better evaluation, the effect of AF17N polymeric nanofilm to the corrosion inhibition property of superhydrophobic AA5052 surface, the cyclic voltammetry (CV) curves of the bare aluminum alloy and the as-prepared superhydrophobic surface were measured in $0.1 \mathrm{~mol} \mathrm{~L}^{-1} \mathrm{NaOH}$ aqueous solution to study the surface coverage of AF17N molecules (Figure 9). Noticeably, the surface covered with or without polymeric nanofilm has significant influence on the general shape of the cyclic voltammograms. For the surface without polymeric nanofilm, the activated anodic peaks at $0.37 \mathrm{~V}$ could be observed. It attributed to the formation of $\mathrm{Ni}(\mathrm{OH})_{2}$ and $\mathrm{Co}(\mathrm{OH})_{2}$ as a result of electro-oxidation of the $\mathrm{Ni}-\mathrm{Co}$ plating. Cathodic peaks at $0.3 \mathrm{~V}$ was resulting from the reduction of $\mathrm{Ni}(\mathrm{OH})_{2}$ and $\mathrm{Co}(\mathrm{OH})_{2}$, respectively. Compared with the surface without polymeric nanofilm, the current and area of the superhydrophobic surface was much smaller. Thus, we can draw a conclusion that the changes observed in the curves of the superhydrophobic surface must result from specific interactions by AF17N monomer. These observations indicate that the oxidative reaction of superhydrophobic surface was highly blocked in alkaline aqueous, demonstrating the AF17N polymeric nanofilm is a good barrier to block charge or reactant ion transmission. It is expected that the resulting AF17N polymeric nanofilm supply excellent corrosion protection for bare aluminum alloy. Perfluoro alkyl chains in the polymer films are perpendicular to the substrate surface [30]. The hydrophobic group can isolate the water molecules effectively and provide good corrosion protection to aluminum alloy. In conclusion, superhydrophobic surfaces were fabricated with the $-\mathrm{CF}_{3}$ group and $-\mathrm{CF}_{2}-$ group of low surface energy from the AF17N. 


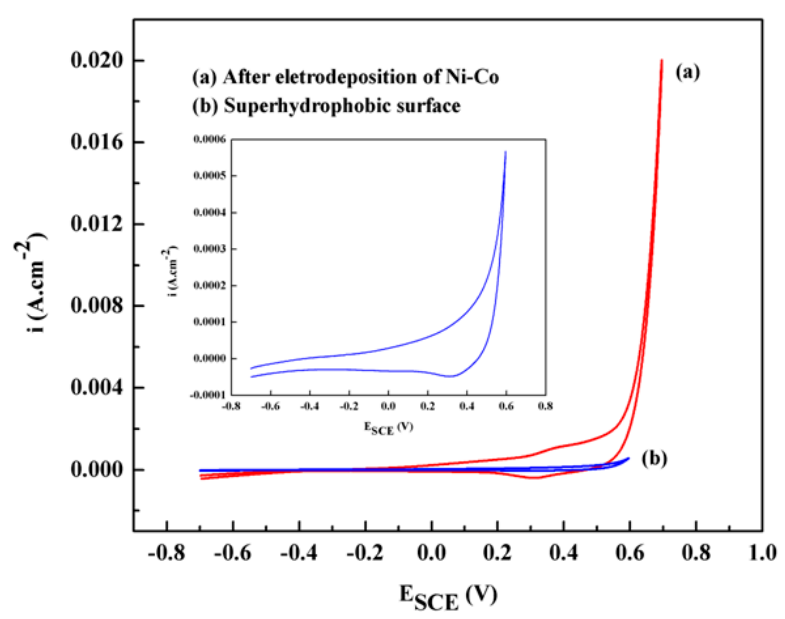

Figure 9. Cyclic voltammorgrams of bare AA5052 aluminum alloy and superhydrophobic surface in $0.1 \% \mathrm{NaOH}$ solution.

\subsection{Self-Cleaning Effect}

The self-cleaning effect is an important character of superhydrophobic surfaces for their applications. The simulation process for the as-prepared superhydrophobic surface was carried out by deliberately sprinkling $\mathrm{Al}_{2} \mathrm{O}_{3}$ powder on the sample surface as a model dust contaminant. Figure 10 shows the evolution process of the self-cleaning effect, which was recorded by a digital camera at a speed of 60 frames per second. The sample with superhydrophobic surface was placed with a tilting angle of about $5^{\circ}$ above horizontal and then a water droplet was dropped to the contaminant surface. When a water droplet was dropped to the sample surface, it rolled off immediately with removing all the $\mathrm{Al}_{2} \mathrm{O}_{3}$ powder along the path of the droplet. Amazingly, it was observed that the water droplet maintained its almost spherical shape. This result means that the as-prepared surface has an excellent self-cleaning effect due to the superior superhydrophobic property.

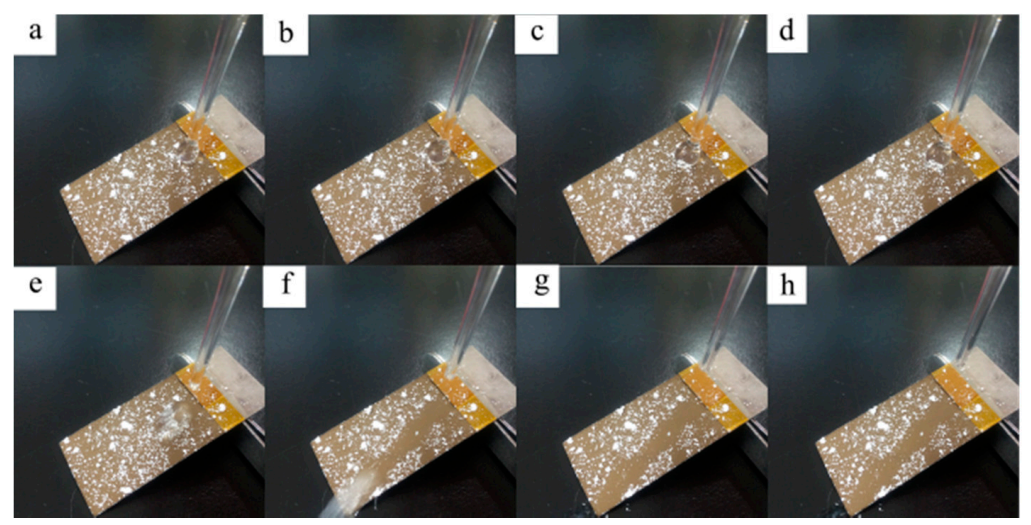

Figure 10. The time sequence of the self-cleaning process on the superhydrophobic surface at a sliding angle about $5^{\circ}$.

\section{Conclusions}

In summary, a functional superhydrophobic surface was successfully fabricated on AA5052 aluminum alloy by electrodeposition of $\mathrm{Ni}-\mathrm{Co}$ films and surface modification with AF17N. The as-prepared superhydrophobic surface with hierarchical nano/micro structures has a high contact angle of $167.3^{\circ} \pm 1.3^{\circ}$ and an ultra-low sliding angle of about $1^{\circ}$. It was found that the superhydrophobicity was governed by both geometrical microstructures and the surface chemical composition. Electrochemical measurements showed that the as-prepared sample possessed a better corrosion resistance than bare aluminum alloy, indicating that the superhydrophobic surface can 
effectively protect aluminum alloy from corrosion. Furthermore, the resulting superhydrophobic surface has good chemical stability and long-term durability as well as self-cleaning effect. This method is of great value for industrial preparation of superhydrophobic surfaces and it is also meaningful for extending the applications in other relevant engineered materials fields.

Author Contributions: Conceptualization and Methodology, F.W. and Q.Z.; Software, Validation, Investigation and Data Curation, Q.Z. and T.T.; Writing-Original Draft Preparation, Q.Z.; Writing-Review \& Editing, F.W., Supervision, F.W.; Project Administration and Funding Acquisition, F.W. and Q.Z.

Funding: This research was supported by the Fundamental Research Funds for the Central Universities (No. QN2013085), the Natural Science Basic Research Plan in the Shaanxi Province of China (No. 2018JQ5191), the Young Talent fund of University Association for Science and Technology in Shaanxi, China (No. 20180419) and the Doctoral Scientific Research Foundation of Baoji University of Arts and Sciences (No. ZK2018044).

Conflicts of Interest: The authors declare no conflict of interest.

\section{References}

1. Loto, R.T.; Adeleke, A. Corrosion of aluminum alloy metal matrix composites in neutral chloride solutions. J. Fail. Anal. Prev. 2016, 16, 874-885. [CrossRef]

2. Quazi, M.M.; Fazal, M.A.; Haseeb, A.S.M.A.; Yusof, F.; Masjuki, H.H.; Arslan, A. Laser-based surface modifications of aluminum and its alloys. Crit. Rev. Solid State Mater. Sci. 2016, 41, 106-131. [CrossRef]

3. Barati Darband, G.; Aliofkhazraei, M.; Khorsand, S.; Sokhanvar, S.; Kaboli, A. Science and engineering of superhydrophobic surfaces: Review of corrosion resistance, chemical and mechanical stability. Arab. J. Chem. 2018, in press. [CrossRef]

4. Gudić, S.; Vrsalović, L.; Kliškić, M.; Jerković, I.; Radonić, A.; Zekić, M. Corrosion inhibition of aa 5052 aluminium alloy in nacl solution by different types of honey. Int. J. Electrochem. Sci. 2016, 11, 998-1011.

5. Uwiringiyimana, E.; O'Donnell, P.S.; Joseph, I.V.; Adams, F.V. The effect of corrosion inhibitors on stainless steels and aluminium alloys: A review. Afr. J. Pure Appl. Chem. 2016, 10, $23-32$.

6. Singh, B.P.; Jena, B.K.; Bhattacharjee, S.; Besra, L. Development of oxidation and corrosion resistance hydrophobic graphene oxide-polymer composite coating on copper. Surf. Coat. Technol. 2013, 232, 475-481. [CrossRef]

7. Asmone, A.S.; Chew, M.Y.L. An investigation of superhydrophobic self-cleaning applications on external building façade systems in the tropics. J. Build. Eng. 2018, 17, 167-173. [CrossRef]

8. Emelyanenko, A.M.; Boinovich, L.B.; Bezdomnikov, A.A.; Chulkova, E.V.; Emelyanenko, K.A. Reinforced superhydrophobic coating on silicone rubber for longstanding anti-icing performance in severe conditions. Acs Appl. Mater. Interface 2017, 9, 24210-24219. [CrossRef] [PubMed]

9. Nguyen, T.B.; Park, S.; Lim, H. Effects of morphology parameters on anti-icing performance in superhydrophobic surfaces. Appl. Surf. Sci. 2018, 435, 585-591. [CrossRef]

10. Wei, C.; Dai, F.; Lin, L.; An, Z.; He, Y.; Chen, X.; Chen, L.; Zhao, Y. Simplified and robust adhesive-free superhydrophobic $\mathrm{SiO}_{2}$-decorated pvdf membranes for efficient oil/water separation. J. Membr. Sci. 2018, 555, 220-228. [CrossRef]

11. Li, H.; Zhao, X.; Wu, P.; Zhang, S.; Geng, B. Facile preparation of superhydrophobic and superoleophilic porous polymer membranes for oil/water separation from a polyarylester polydimethylsiloxane block copolymer. J. Mater. Sci. 2016, 51, 3211-3218. [CrossRef]

12. Yagüe, J.L.; Segadó, P.; Auset, M.; Borrós, S. Textured superhydrophobic films on copper prepared using solvent-free methods exhibiting antifouling properties. Thin Solid Film 2017, 635, 32-36. [CrossRef]

13. Mohamed, A.M.A.; Abdullah, A.M.; Younan, N.A. Corrosion behavior of superhydrophobic surfaces: A review. Arab. J. Chem. 2015, 8, 749-765. [CrossRef]

14. Yan, Y.Y.; Gao, N.; Barthlott, W. Mimicking natural superhydrophobic surfaces and grasping the wetting process: A review on recent progress in preparing superhydrophobic surfaces. Adv. Coll. Interface Sci. 2011, 169, 80-105. [CrossRef] [PubMed]

15. Liu, Y.; Liu, J.; Li, S.; Han, Z.; Yu, S.; Ren, L. Fabrication of biomimetic super-hydrophobic surface on aluminum alloy. J. Mater. Sci. 2014, 49, 1624-1629. [CrossRef] 
16. Dey, S.; Chatterjee, S.; Singh, B.P.; Bhattacharjee, S.; Rout, T.K.; Sengupta, D.K.; Besra, L. Development of superhydrophobic corrosion resistance coating on mild steel by electrophoretic deposition. Surf. Coat. Technol. 2018, 72, 220-235. [CrossRef]

17. Qian, H.C.; Li, H.Y.; Zhang, D.W. Research progress of superhydrophobic surface technologies in the field of corrosion protection. Surf. Technol. 2015, 3, 15-24.

18. Hoshian, S.; Jokinen, V.; Somerkivi, V.; Lokanathan, A.R.; Franssila, S. Robust superhydrophobic silicon without a low surface-energy (hydrophobic) coating. ACS Appl. Mater. Interface 2015, 7, 941-950. [CrossRef] [PubMed]

19. Wang, J.; Liu, F.; Chen, H.; Chen, D. Superhydrophobic behavior achieved from hydrophilic surfaces. Appl. Phys. Lett. 2009, 95, 3063-3067. [CrossRef]

20. Forooshani, H.M.; Aliofkhazraei, M.; Rouhaghdam, A.S. Superhydrophobic aluminum surfaces by mechanical/chemical combined method and its corrosion behavior. J. Taiwan Inst. Chem. Eng. 2017, 72, 220-235. [CrossRef]

21. Xiong, J.; Sarkar, D.K.; Chen, X.G. Superhydrophobic honeycomb-like cobalt stearate thin films on aluminum with excellent anti-corrosion properties. Appl. Surf. Sci. 2017, 407, 361-370. [CrossRef]

22. Karthik, N.; Yong, R.L.; Sethuraman, M.G. Fabrication of corrosion resistant mussel-yarn like superhydrophobic composite coating on aluminum surface. J. Taiwan Inst. Chem. Eng. 2017, 77, 302-310. [CrossRef]

23. Kang, Z.; Ye, Q.; Sang, J.; Li, Y. Fabrication of super-hydrophobic surface on copper surface by polymer plating. J. Mater. Process. Technol. 2009, 209, 4543-4547. [CrossRef]

24. Fang, W.; Wang, Y.; Li, Y.; Qian, W. Fabrication of triazinedithiol functional polymeric nanofilm by potentiostatic polymerization on aluminum surface. Appl. Surf. Sci. 2011, 257, 2423-2427.

25. Zhao, Q.; Tang, T.; Dang, P.; Zhang, Z.; Wang, F. Preparation and analysis of complex barrier layer of heterocyclic and long-chain organosilane on copper alloy surface. Metals 2016, 6, 162. [CrossRef]

26. Zhao, Q.; Tang, T.; Dang, P.; Zhang, Z.; Wang, F. The corrosion inhibition effect of triazinedithiol inhibitors for aluminum alloy in a $1 \mathrm{~m}$ hcl solution. Metals 2017, 7, 44. [CrossRef]

27. Mori, K.; Hirahara, H.; Oishi, Y.; Kumagai, N. Effect of triazine dithiols on the polymer plating of magnesium alloys. Mater. Sci. Forum 2000, 350, 223-234. [CrossRef]

28. She, Z.; Li, Q.; Wang, Z.; Tan, C.; Zhou, J.; Li, L. Highly anticorrosion, self-cleaning superhydrophobic Ni-Co surface fabricated on AZ91D magnesium alloy. Surf. Coat. Technol. 2014, 251, 7-14. [CrossRef]

29. Cassie, A.B.D. Wettability of porous surfaces. Trans. Faraday Soc. 1944, 40, 546-551. [CrossRef]

30. Lee, Y.; Ju, K.Y.; Lee, J.K. Stable biomimetic superhydrophobic surfaces fabricated by polymer replication method from hierarchically structured surfaces of al templates. Langmuir 2010, 26, 14103-14110. [CrossRef] [PubMed]

(c) 2018 by the authors. Licensee MDPI, Basel, Switzerland. This article is an open access article distributed under the terms and conditions of the Creative Commons Attribution (CC BY) license (http:/ / creativecommons.org/licenses/by/4.0/). 